\title{
The Effect of Build Orientation on the Surface Quality, Microstructure and Mechanical Properties of Selective Laser Melting 316L Stainless Steel
}

\author{
Hamza Alsalla* $*^{\dagger} \quad$ Liang Hao Christopher Smith \\ College of Engineering, Mathematics and Physical Sciences, University of Exeter, Exeter \\ EX4 4QF, Devon, United Kingdom \\ ${ }^{\dagger}$ Technical College of Civil aviation and Meteorology, Esbeah, Libya
}

\begin{abstract}
Selective laser Melting (SLM) is an additive manufacturing technique for three dimensional parts. The process parameters are known to affect the properties of the eventual part. In this study, process parameters were investigated in the building of 316L structures at a variety of building orientations and for which the fracture toughness was measured. The relationship between the process parameters, microstructure, surface quality and toughness has not previously been reported. Hardness and tensile tests were carried out to evaluate the effect of consolidation on the mechanical performance of specimens. Optical and electron microscopy were used to characterise the microstructure of the SLM specimens and their effects on properties relating to fracture and the mechanics. It was found that the density of built samples is $96 \%$ and the hardness is similar in comparison to conventional material. The highest fracture toughness value was found to be $176 \mathrm{MPa} \mathrm{m}^{1 / 2}$ in the $\mathrm{xz}$ building direction, and the lowest value was $145 \mathrm{MPa} \mathrm{m} 1 / 2$ in the $\mathrm{z}$ building direction. This was due to pores and some cracks at the edge, which are slightly lower in comparison to a conventional product. The build direction does have an effect on the microstructure of parts, which subsequently has an effect upon their mechanical properties and surface quality. Dendritic grain structures were found in $\mathrm{xz}$ samples due to the high temperature gradient, fast cooling rate and reduced porosity. The tensile properties of such parts were found to be better than those made from conventional material.
\end{abstract}

\section{Keywords}

Direct Metal Laser Sintering, Steel Alloy, Microstructure, Tensile behaviour, Fracture toughness, Surface roughness

*Corresponding author. College of Engineering, Mathematics and Physical Sciences, University of Exeter, Exeter EX4 4QF, Devon, United Kingdom, 00447400622226

E-mail addresses: alsallah@yahoo.com, and hhra201@exeter.ac.uk 


\section{Introduction}

Stainless steels are widely used as feed powder materials within Selective Laser Melting (SLM) due to their comparatively low cost, their safety and their ease of use. 316L stainless steel is a common alloy that is used in aerospace applications due to its resistance to corrosion and good specific strength (Yan, Hao, Hussein, \& Raymont, 2012). The SLM of 316L stainless steel was previously investigated in order to illustrate the effect of the process parameters on the density, the mechanical properties (Childs \& Hauser, 2005; Childs, Hauser, \& Badrossamay, 2005), and to look for defects, such as porosity, cracks and balling, which were found to occur in SLM produced parts. Different SLM processing parameters, including laser power, scan speed, layer thickness, and hatch distance, have been examined in previous studies, however, the understanding of the inter-relationship between these parameters is still not clear, in particular in relation to the effect of balling (Tolochko et al., 2004), the interaction mechanism between material and laser beam (Fischer et al., 2003), and the powder solidification on the substrate (Schoinochoritis, Chantzis, \& Salonitis, 2015). Earlier studies have yet to apply SLM to make 316 stainless steel parts with mechanical properties that are sufficient for use in applications (Zhang, Klemm, Eckert, Hao, \& Sercombe, 2011). There is also a limited characterisation of the critical mechanical properties for aerospace applications, particularly for fracture toughness, which hasn't been tested in different build directions (Kruth et al., 2010). So there is a need for an in-depth and systematic study on the SLM processing of stainless steel for aerospace applications. This is essential both in order to further improve the capability of SLM to process $316 \mathrm{~L}$, and for the resulting properties of parts for aerospace applications. A systematic study is required to provide a clear understanding of the fundamental process mechanisms governing the resulting microstructure; and thus the properties of $316 \mathrm{~L}$ parts.

The research presented in this study has focused on analysis of the mechanical properties and microstructures of SLM fabricated parts made with 316L steel, and, in particular, on the effect of build orientation on these properties. Firstly, the effect of build orientation on the toughness properties, strength and ductility of the SLM fabricated stainless steels was investigated. Secondly, the microstructure of the SLM parts was characterised, and their effects on mechanical properties, in particular on fracture toughness, were evaluated. These measured properties were compared with previous research, providing an understanding of SLM processing for different metal alloys. The findings of this study provide new knowledge about the use of the SLM process for the fabrication of stainless steel aerospace components. 


\section{Experimental Procedures}

Fifteen sets of 316L stainless steel flat samples for tensile testing, and fifteen sets of Single Edge Notched Bend (SENB) samples for fracture toughness testing were produced using SLM (M1 CUSING, Concept Laser Ltd). The samples were produced in different build orientations, which were named the ox, oz. and six orientations, as shown in Figure 1. The SLM machine has a base plate with axes $\mathrm{x}$ and $\mathrm{y}$, and a build direction in the $\mathrm{z}$ axis. The naming convention uses two letters. The first letter is the axis of the machine in which the longest axis of the sample lies. The second letter is the machine axis in which the second longest sample axis lies. These sets were designed to investigate the effects of different building layouts and orientations on the properties of the SLM stainless steel parts. In Figure 1 , the samples, made in three different build directions were produced with a laser power of $180 \mathrm{~W}$, a scan speed of $1600 \mathrm{~mm} / \mathrm{s}$, a layer thickness of $30 \mathrm{am}$, and a scanning laser spot with a 75 am diameter.

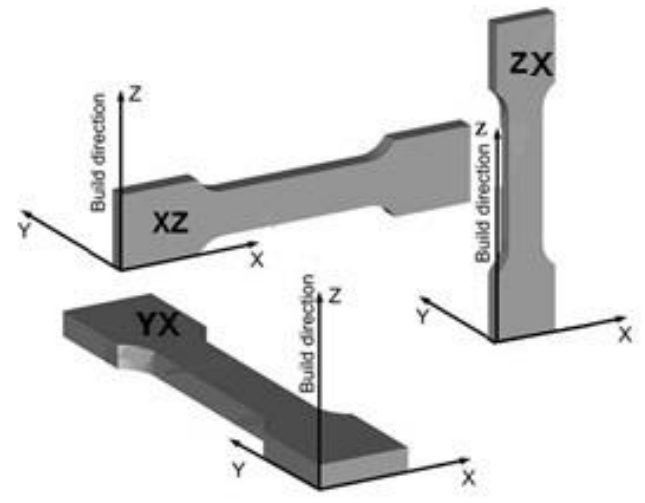

(a)

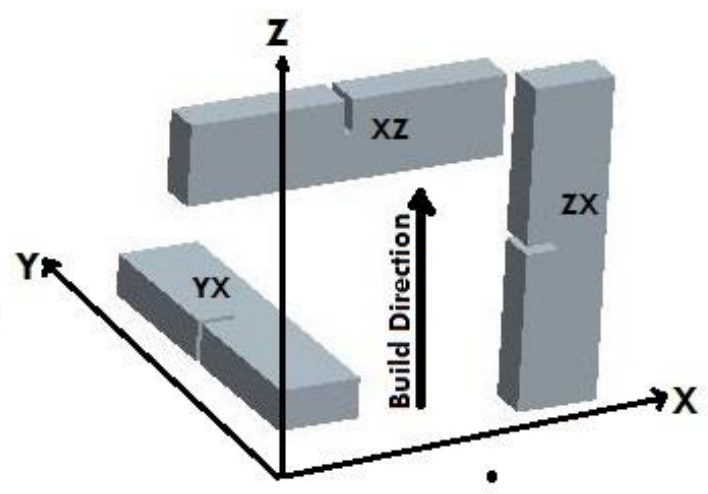

(b)

Fig.1: The SLM fabrication of (a) tensile and (b) fracture toughness testing samples produced at the ox, oz. and six building orientations

After removal from the plate, all the SLM fabricated samples were machined to remove the remaining support structure and were then tested in an as-built condition. For each direction, five specimens were built for the tensile testing and five for fracture toughness testing. The densities of these specimens were evaluated by two methods, direct measurements, by determining their weight and dimensions (mass / volume), and the Archimedes principle. All of the specimens were pulled until they fractured for the tensile testing, and the toughness notched specimens were subjected to a three points test through compression to failure. All of the samples produced were manufactured and tested according to ASTM E8 and ASTM E399-9, for tensile and fracture toughness tests, respectively.

The metallographic investigations were carried out for the samples that were etched in a solution containing $122 \mathrm{ml}$ Alcohol, $122 \mathrm{ml}$ hydrochloric acid, and 6ml Nitric acid. The SEM and Optical microscopy were used to characterise the surface morphology and 
microstructural features of the specimens. The samples were analysed for the actual surface at different building strategies by surface profilometer (Talyscan-150, Taylor Hobson Ltd), the data were collected through two measurements, measured on the parallel and perpendicular to the building direction. The average values of $\mathrm{Ra}$ were obtained from both parallel and perpendicular measurements.

\section{Result and discussion}

\subsection{Density Analysis}

The first, and most important, concern about the use of the SLM process is the density of the fabricated parts, as this has a direct influence on the product's performance and mechanical properties (Morgan, Sutcliffe, \& O'Neill, 2004). The result exhibited the same density for ox, oz. and six parts at $7.7 \mathrm{~g} / \mathrm{cm}^{3}$, with a standard deviation of \pm 0.01 . The samples that were built in the six directions represented a larger building height and, consequently, there are a larger numbers of layers. Each layer of the $z$ built group has a relatively smaller cross section than that of the ox and oz. groups, its external surface boundary is more likely to be bonded with the semi-melted particles after its exposure to, and interaction with, the laser beam scanning. Overall, the effect of the building directions on the density of the SLM parts is very minimal. In general, post polishing or machining would be applied to the SLM parts for aerospace application. The average density of $7.7 \mathrm{~g} / \mathrm{cm}^{3}$ for the SLM stainless group accounts for $96 \%$ of the density of $8 \mathrm{~g} / \mathrm{cm}^{3}$ for AISI 316L stainless steel which is made by conventional production means. This experimental density result is slightly lower in comparison to a previous study, which achieved $99 \%$ of the density of $8 \mathrm{~g} / \mathrm{cm}^{3}$ (Yasa \& Kruth, 2011). This previous study showed that the preheating temperature plays an important role in the SLM process, and high-density parts of $99 \%$ are made when a high preheated temperature of the powder bed of $150 \mathrm{C}^{\circ}$ and $200 \mathrm{C}^{\circ}$ is used. The laser re-melting may be another approach to enhancing the density of SLM parts as it allows porosity of about $0.77 \%$ for the parts with no laser re-melting to $0.036 \%$ for the parts with laser re-melting when the parameters selected properly (Boisselier \& Sankaré, 2012).

In general, the SLM process is required to produce fully dense parts in order to meet strict mechanical property requirement for aerospace application. However, it might be difficult to achieve complete metal powder densification during the SLM process since there is no mechanical pressure applied to metal powder, as in moulding process. The metal powder densification during SLM is predominantly influenced by temperature, capillary force and gravity (Kruth et al., 2010). Gas bubbles can be entrapped in the powder material through the SLM's solidification. The dissolved element's solubility was decreased through solidification in the melt pool (Marleen Rombouts, 2006). Hence, further research and development on 
SLM is still required in order to deliver high-density stainless steel components for aerospace applications. Future research should provide an in-depth understanding of the laser material interaction mechanism in order to manipulate the powder consolidation and to achieve enhanced densification.

\subsection{Surface and cross-section microstructure}

Figure 2 shows different views (both parallel and perpendicular to the build direction) of the microstructure of ox, oz. and six samples. Densification is clearly a little more complete in the oz. and six samples, since they exhibit fewer voids and pores, due to the short scanning length when compared to samples built in the ox direction. We define 'pores' as being empty spaces in the sample following manufacture, and 'voids' as being empty spaces brought into existence by fracture of un-melted particles left over from manufacture. At the overlap joint zone (this phenomena occurs when a short distance between the scan tracks), the additional heat was transferred from the melted track to the previous solidified track, leading to better consolidation and densification. The microscope shows that the scan tracks are clearly distinguishable in Figure 2 (b), and (c) through a few large pores that are caused by the balling phenomena in Figure 2 (c), the dark band areas are present due to etchant. The crosssection images show that the stainless steel powder particles also melt well. 

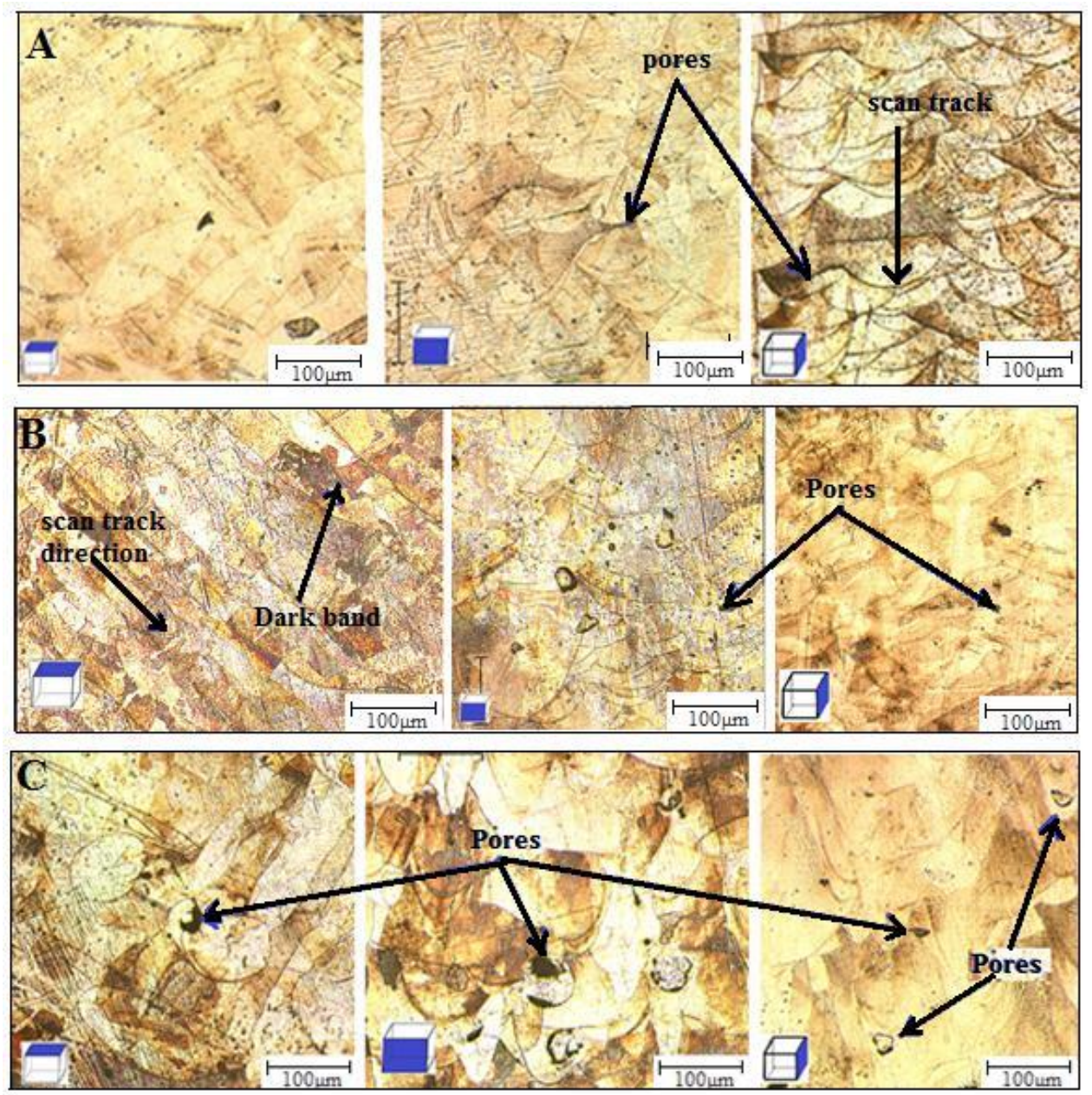

Fig, 2: shows parallel and perpendicular to build direction side walls views of 316L stainless steel SLM samples (polished and etched). (a) In the yx. (b) xz. (c) zx, build directions.

Figure 3 presents the region between the scanning tracks of the material where the melting shows good diffusion. Fine dendritic structures are presented in the perpendicular view in the very dense $\mathrm{xz}$ samples, whereas some pores and voids are shown in the yx and zx samples. The microstructure of parts produced in this study varies in different directions. Gäumann et al have shown that the quality of metal parts formed by laser melting depends on the thermal gradient and growth speed (Gäumann, Henry, Cleton, Wagniere, \& Kurz, 1999). Rombouts also found similar microstructures had formed as the result of rapid solidification due to a high cooling rate (Marleen Rombouts, 2006). The small pores found in $\mathrm{xy}$ and $\mathrm{z}$ build samples can be explained through three different resources - i) incomplete melting, ii) shrinkage, and iii) the composition of gas voids (balling) (Hao, Dadbakhsh, Seaman, \& Felstead, 2009). These small pores have an average size of $8 \mu \mathrm{m}$ and are probably produced as a result of shrinkage and balling due to the solidification phenomena. In Figure 3 it was observed that the pores in zx samples have an irregular shape and appear more frequently than in samples built in the yx direction, while samples built in the $\mathrm{xz}$ direction reveal no pores, implying good consolidation which can be observed through the dendritic 
microstructure. This porosity may concentrate stress through mechanical loading and can increase during applied stress. Soboyejo (Soboyejo, 2002) reported that the growth of three dimensional defects may lead finally to catastrophic failure in the structure and in engineering components. Consequently, it is axiomatic that these pores affect the mechanical properties, especially tensile strength, elongation and fracture toughness, and should show fewer properties than those found in conventional material (this will be further clarified in Section 3.4).
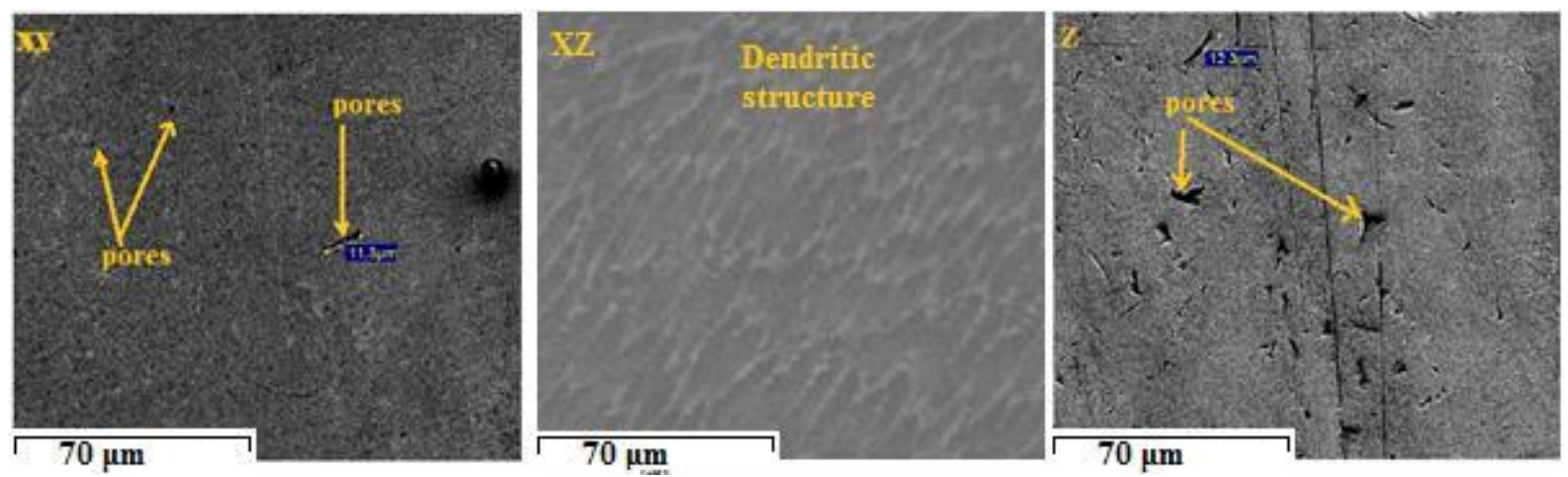

Fig: 3 SEM images for Top Side walls views of 316L stainless steel parts built in the yx, xz and zx directions, $500 \mathrm{x}$ magnifications.

Figure 4 presents optical microscopy (OM) and SEM images of the xz build direction sample, where the dendrite arms were normal to the surface. So, this structure showed that the solidification is dendritic or cellular, with a size of about $3 \mu \mathrm{m}$, and also in Figure $6.5 \mathrm{~b}$ higher magnification reveals that the intercellular spacing is less than $1 \mu \mathrm{m}$, which contributes to the excellent strength that can be achieved, both in processed and aged conditions (Cherry et al., 2015; Gu \& Shen, 2009; Kruth et al., 2010). Though previous research in SLM processing has found that these microstructures are common, this microstructure is formed as result of high thermal gradients and rapid solidification, due to a very high cooling rate, and this helps to reduce crack nucleation at the pores between scan tracks (Takalo, Suutala, \& Moisio, 1979). The tensile strength significantly increases as a result of the amount of primary austenite dendrites in the multi alloy. This microstructure has been reported in previous studies, and was explained by the relation between dendrites and mechanical properties (Kaiser, Williamson, O’Brien, Ramirez-Garcia, \& Browne, 2013). 

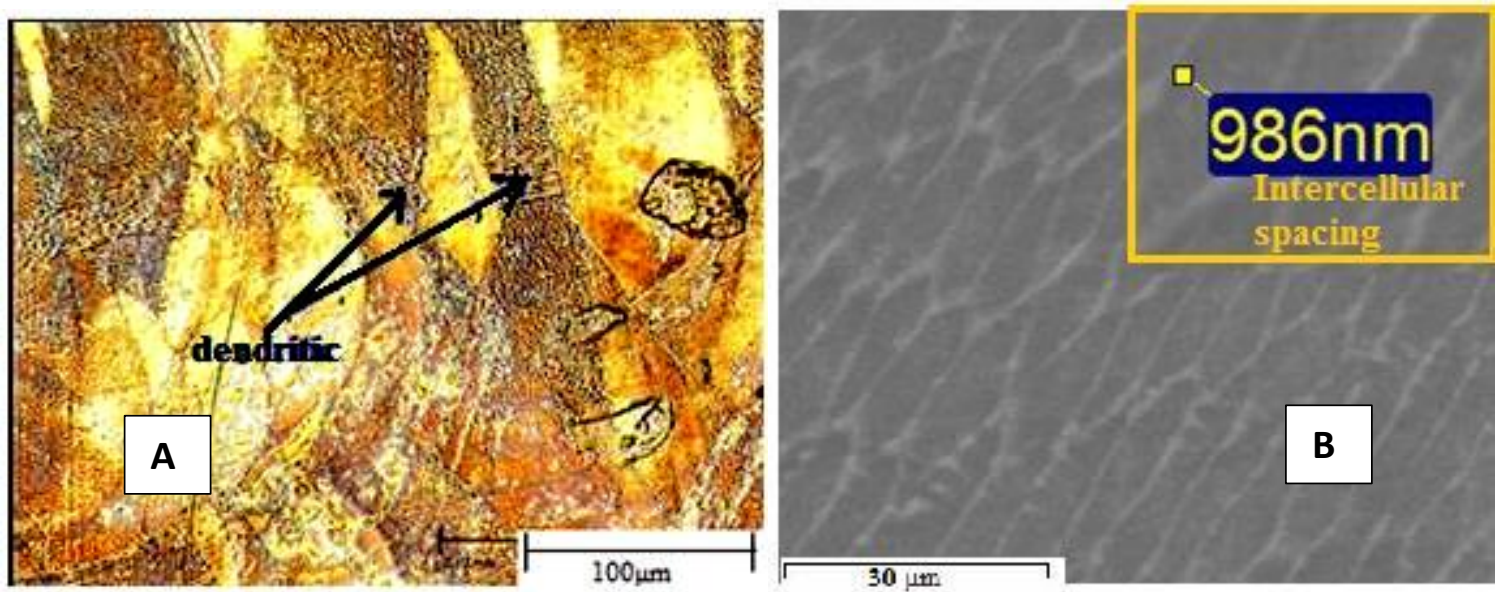

Fig, 4: shows the microstructure of the xz build direction sample (a) optical microscopy image showing dendritic arms from the side view of the 316L sample (b) SEM image at 1000x magnification reveals dendritic arms.

There are correlations between dendrite arm spacing and mechanical properties, such as yield strength, hardness and ultimate tensile strength (Chirita, Stefanescu, Cruz, Soares, \& Silva, 2010). Generally, a refinement of the microstructure or grain leads to improved mechanical properties. The dendrite arm spacing was found to be significantly affected by the different cooling conditions (Ejiofor \& Reddy, 1997). So, it is important to understand the microstructure of material from different views, because the overlapping of the laser's scanning track can produce defects, such as cracks and voids. Such defects, when located at the interface between the rows and scanning tracks, are known to produce a point that is vulnerable to crack growth. Since the temperature gradient and local heat transfer conditions determine the grain growth in the parts that are produced by SLM (Kruth et al., 2010), it is expected that changing the process parameter, as well as the build direction, may affect the microstructure of the parts and the mechanical properties of hardness, ultimate tensile strength and yield strength could all be increased with an increase in the cooling rate, while the ductility decreased gradually (Kaiser et al., 2013; Mallapur, Rajendra Udupa, \& Kori, 2010; Osorio, Goulart, Garcia, Santos, \& Neto, 2006).

\subsection{Mechanical properties}

\subsubsection{Tensile test}

Figure 5 reveals the tensile stress-strain curves that were calculated for the $\mathrm{yx}, \mathrm{xz}$ and $\mathrm{zx}$ build direction. The elastic slope in this figure is usually named the Apparent Young's Modulus. The total elongation to rupture, the ultimate and yield strength were determined after examination of the plastic and elastic parts of the curves; see Table 1 and Figure 6 . The total elongations were found to be between $35 \%$ and $41 \%$ and these results corroborate with 
the results presented in previous studies that were carried out by John and Yang et al and the ultimate tensile strength (UTS) recorded a large difference from $564 \mathrm{MPa}$ for the zx samples, to $695 \mathrm{MPa}$ for the xz samples (standard deviation $3 \mathrm{MPa}$ ) (John, 2001) (Yang, Lu, Luo, \& Wang, 2012), The lowest value of UTS was recorded in the $\mathrm{z}$ samples, because of the number of irregular pores (see Fig 3) and the presence of a weak region between the scanning tracks and the melting layers where all the fractures had occurred. On the other hand, the yield strength varied from 387 in the zx samples to $423 \mathrm{MPa}$ in the $\mathrm{xz}$ samples, and was situated above the previous research results of 261MPa (de Lima \& Sankaré, 2014; John, 2001).

This enhancement in the tensile properties was due to the proper selection of the process parameters. For example, the width of hatch spacing: $70 \mu \mathrm{m}$ was reasonable in order to ensure good consolidation, as opposed to a $120 \mu \mathrm{m}$ hatch spacing, which had been applied previously and was to leave some gaps un-melted or partially melted between the tracks. From Table 1, it was noted that the samples built in the xz direction show the highest performance. This is owing to fewer pores and voids being present and finer grains (dendrite microstructures), as shown in Figures $4 \mathrm{a}$ and $4 \mathrm{~b}$. Generally, the tensile properties obtained in this experiment are high in comparison to previous studies, and they seem to be usable for aerospace applications. Consequently, the mechanical properties of the SLM of 316L stainless steel depend not only on the material composition, but also on build direction. In the meantime, it must be borne in mind that the defects, such as cracks and pores, which occur following the SLM process, can be reduced by post process treatment and residual stress relief to further improve the tensile strength and the fracture toughness.

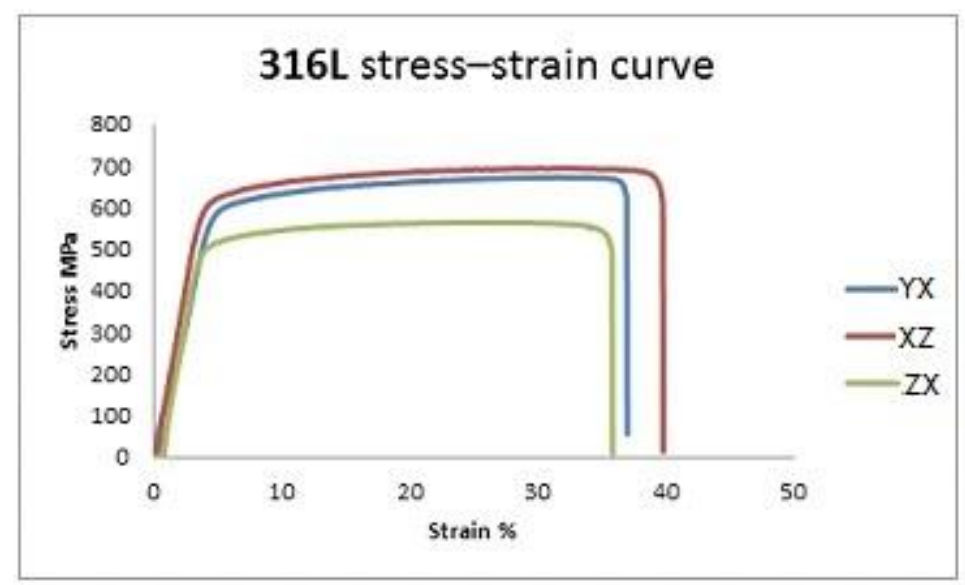

Fig.5: Tensile stress-strain curve for the SLM of 316L stainless steel built in different directions. 
Table 1: Tensile properties obtained from the316L stainless steel made by SLM in different directions.

\begin{tabular}{cccc}
\hline As Built Samples & UTS (MPa) & $\begin{array}{c}\text { Yield strength } \\
(\mathrm{MPa})\end{array}$ & Elongation \% \\
\hline YX & $668 \pm 3$ & $397 \pm 3$ & $37 \pm 1$ \\
XZ & $695 \pm 3$ & $423 \pm 3$ & $41 \pm 1.9$ \\
ZX & $564 \pm 3$ & $387 \pm 3$ & $35 \pm 0.6$ \\
t materials & 515 & 205 & 60
\end{tabular}

\subsubsection{Fracture toughness test}

Fracture toughness testing results, presented in Table 2, were calculated according to the maximum flexural load by concentrating the stress in the area of minimum cross section of as built samples made in different build directions, (see Section 2 for test conditions). The fracture toughness varied between $145.5 \mathrm{MPa} \mathrm{m} \mathrm{m}^{1 / 2}$ in the $\mathrm{zx}$ direction (standard deviation \pm 1.1 ) to $176 \mathrm{MPa} \mathrm{m}^{1 / 2}$ in the $\mathrm{xz}$ direction (standard deviation \pm 0.9 ) and a situated low value when compared to the conventional method of austenitic stainless steel grade $316 \mathrm{~L}$, from 112 up to $278 \mathrm{MPa} \mathrm{m}^{1 / 2}$, and 316L annealed stainless steel at $210 \mathrm{MPa} \mathrm{m}^{1 / 2}$ (Maloy et al., 2001). These low values should be caused by the cracks, pores and voids in the parts produced, as well as the residual stress that remains in the 316L parts after the SLM process, are other reasons that affect the mechanical properties of materials, especially fracture toughness.

The differences in the fracture toughness values obtained in this study with different build directions had been anticipated by the previous investigation that is mentioned in Section 3.2 of the microstructure analysis. The tensile test result also showed that the samples built in the $\mathrm{xz}$ direction recorded the highest values of UTS and elongation, meaning that there is a larger area under the stress strain curve, i.e., the material absorbs more energy before failure. These combined values enhance the fracture toughness of parts built in the $\mathrm{xz}$ direction because of the fast cooling rate and the resulting dendritic grain structure. On the other hand, parts built in the yx and zx directions presented slightly lower values of fracture toughness than those built in the $x z$ direction because of the more prevalent and larger pores and defects, especially in the samples built in the zx direction, which were subjected to loading perpendicular to the build direction. The results in Table 2 reveal that the build orientation has a strong effect upon properties. For example, fracture toughness was smallest in the samples built in the $\mathrm{z}$ direction because of the pores, voids and cracks that are present at the edge of the parts. This is shown in Figure $6 \mathrm{c}$, which reveals the fracture surface of the samples. 
In summary, the toughness is the ability of a metal to deform plastically and to absorb energy before rupture. The key to toughness is also a good combination of ductility and strength in these properties, and according to the results obtained in this study they are considered good. Further treatments, such as Hot Isostatic Press HIP, could reduce the amount of residual stress, and also the re-melting of parts is necessary in order to reduce the defects that are mentioned above.

Table 2: presents the fracture toughness property of 316L stainless steel made by SLM in different build directions.

\begin{tabular}{cc}
\hline As Built Sample & fracture toughness $\left(\mathrm{MPa} \mathrm{m}^{1 / 2}\right)$ \\
\hline YX & $152.6 \pm \mathbf{1 . 1 6}$ \\
XZ & $176 \pm 0.9$ \\
ZX & $145.5 \pm \mathbf{1 . 1}$ \\
\hline
\end{tabular}
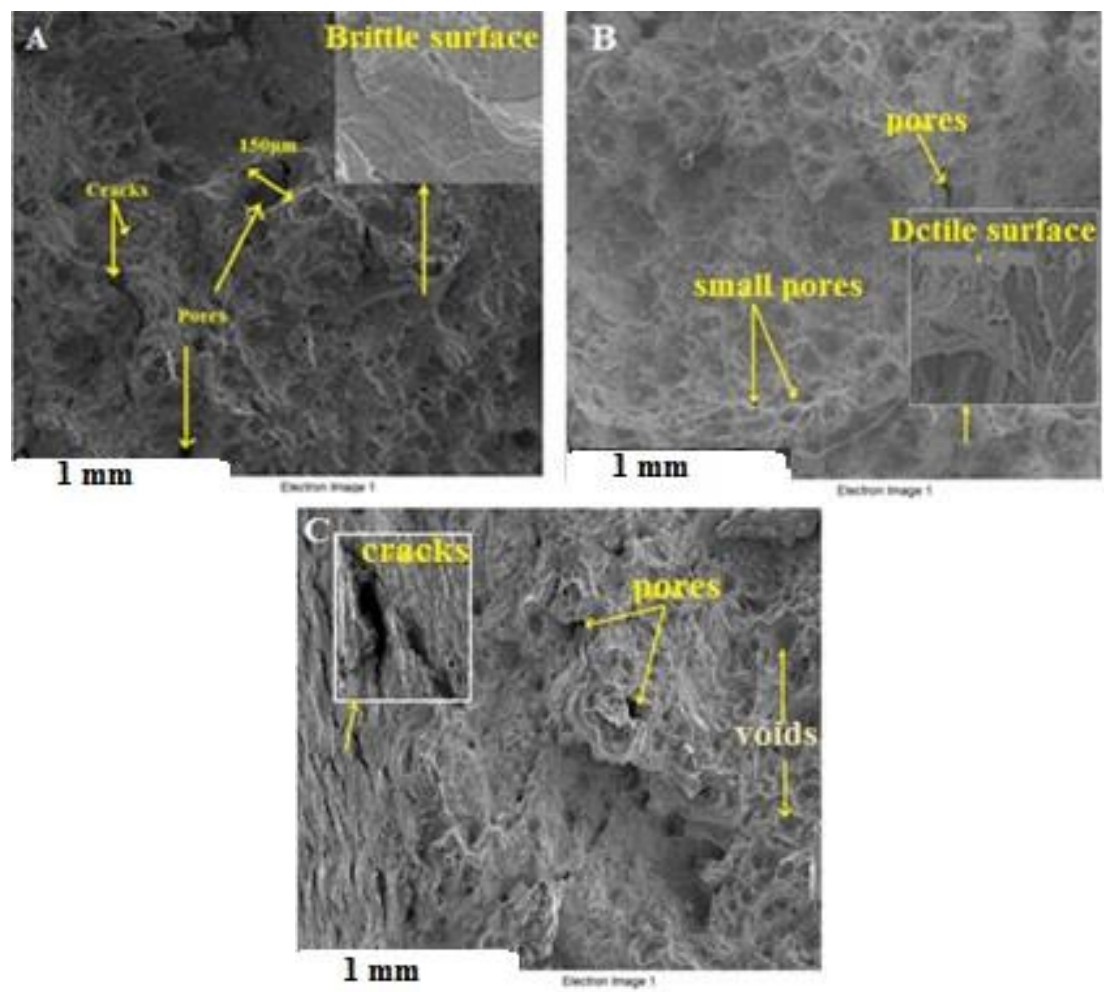

Fig.6: shows SEM images, 30x.Magnification of the fracture surface of 316L stainless steel samples made by SLM in the (a) yx, (b) xz, and (c) zx build directions. 


\subsubsection{Vickers Hardness Test}

The Vickers hardness test for as build samples built in different build orientations was found to demonstrate no significant difference between $226 \mathrm{HV}$ in the xy samples and $221 \mathrm{HV}$ in the $\mathrm{xz}$ and zx samples, with a standard deviation of $2 \mathrm{HV}$. The $\mathrm{xz}$ build records the lowest value of hardness, which means that the samples that were built in the $x z$ direction have more ductility than those built in other directions (as can be noticed in Figure 5) while the zx direction build also has a low hardness due to the porosity that is revealed in this build direction, see table 3. The result presented in this study is similar to those found in conventional products that are made of this alloy, and in a previous study of SLM 316L (Cherry et al., 2015).

Table 3. Vickers Hardness result of 316L stainless steel.

\begin{tabular}{|c|c|c|}
\hline Build Direction & Vickers hardness \pm HV & \pm Stnd Dev HV \\
\hline YX & 226 & 2 \\
XZ & 221 & 2 \\
ZX & 221 & 2 \\
\hline
\end{tabular}

Hardness is the term used to describe the amount of energy required to permanently deform (stretch, bend, compress, etc.) a material. Toughness describes the energy required for fracture. It is often the case that hard materials are not tough, and vice versa (Osakada \& Shiomi, 2006,Leskovšek, Ule, \& Liščić, 2002). In this study, the xz samples showed the least hardness, as shown in Figure 7 , but they also demonstrated the highest fracture toughness, as well as the highest strength and ductility values at $695 \mathrm{MPa}$ and $41 \%$, respectively.

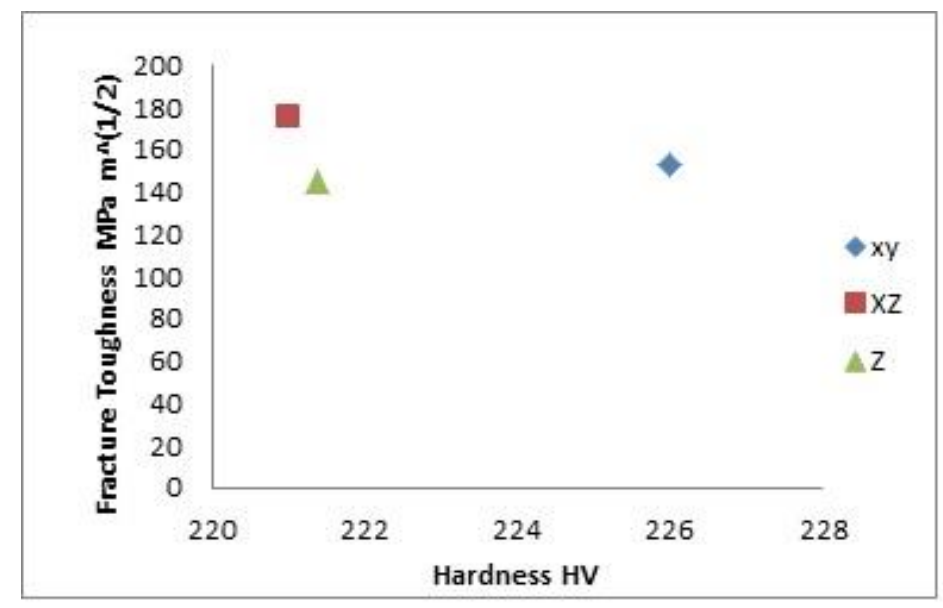

Fig. 7: show the fracture toughness of 316L stainless steel plotted against the hardness HV. 


\subsection{Surface quality}

Figure 8 shows that the surface roughness and the quality of the components produced by SLM of 316L stainless steel does not vary with build direction, but it does vary between surfaces that are perpendicular and parallel to the build direction. Perpendicular surfaces presented the highest values of roughness, with an average of $\mathrm{Ra} 4.25 \mu \mathrm{m}$ (standard deviation of $2.5 \mu \mathrm{m}$ ), while surfaces parallel to the build direction had an average $\mathrm{Ra}$ of $3.1 \mu \mathrm{m}$ (standard deviation of $1.2 \mu \mathrm{m}$ ). These differences are related to the occurrence of an elevated solidification ridge at the edge of the sample, see Figure 9 a. These ridges may affect the dimensional accuracy of a part. However, the parallel surfaces were affected by partially melted powder particles clinging to the surface. Mumtaz and Hopkinson found that surface roughness was generated by the rippling effect that can occur during SLM, when the laser, moving the temperature gradient between the solidifying zone, produces a shear force on the liquid surface, which is contrasted by the surface tension force(Mumtaz \& Hopkinson, 2010). This shear force results in the formation of residual rippling on the surface as the relaxation process could not be fully realised on occasions due to the extremely short solidification times of the melt pool, (Kruth et al., 2010; Strano, Hao, Everson, \& Evans, 2013). These experimental results agree well with previous studies (Badrossamay \& Childs, 2006; Chen, Xie, \& Fox, 2004; M Rombouts, Froyen, Bourell, \& Kruth, 2005) which showed that SLM has not yet achieved high surface quality of components. This is still one of the major drawbacks of the process, particularly in the fabrication of high performance aerospace components. This issue has to be further addressed by applying new process parameters, such as re melting, which has been applied previously, and thus to reduce the surface roughness from $12 \mu \mathrm{m}$ to $1.5 \mu \mathrm{m}$, as shown in Figure $9 \mathrm{~b}$ (Kruth et al., 2010), or a number of surface modifications, such as machining and etching oxidation. The etching solution could be applied as a post-process to enhance the surface quality. In this experiment, all the investigations were done for as build samples and without any re-melting in order to reduce the energy consumed and the production costs. 


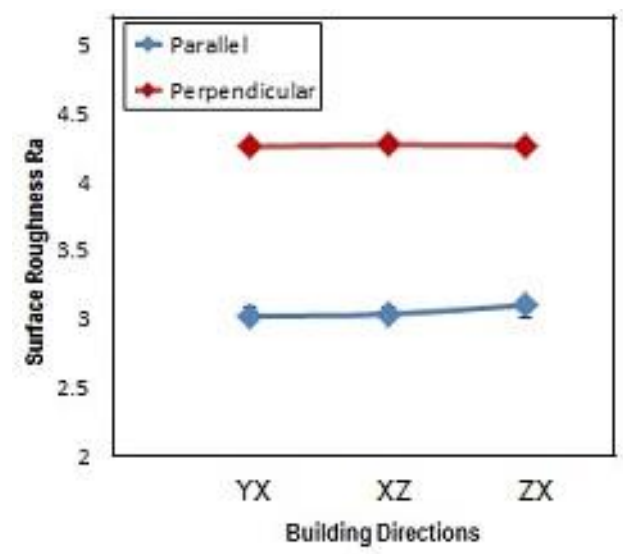

Fig.8: shows the effect of different build directions on the surface roughness of SLM 316L stainless steel parts made by SLM.

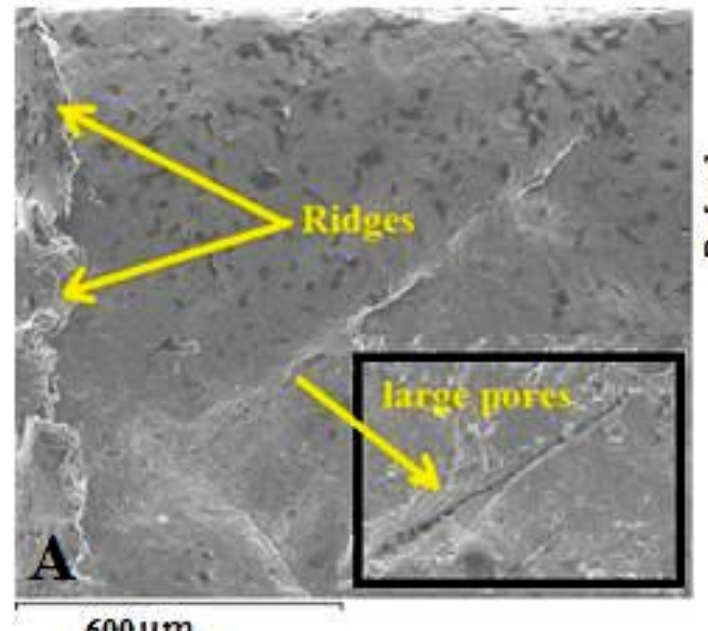

$600 \mu \mathrm{m}$

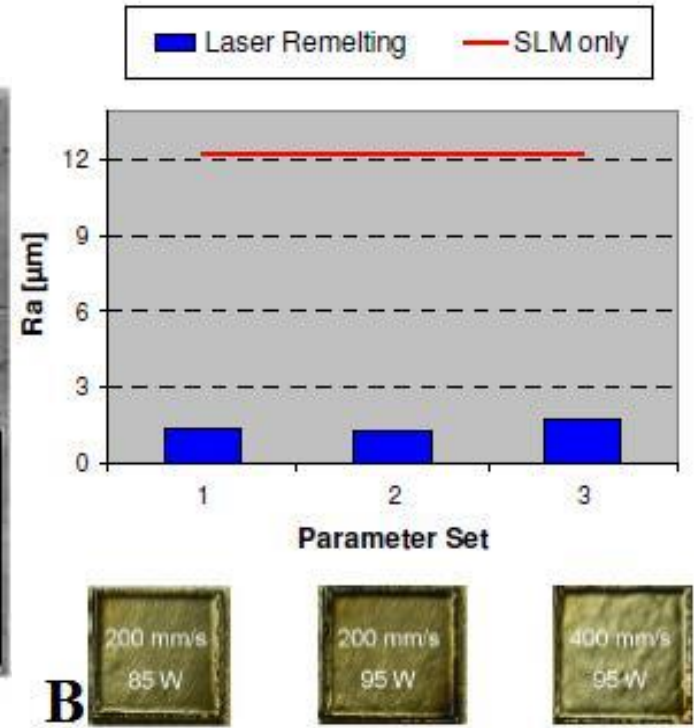

Fig: 9. (a) SEM image of an yx sample. (b) Roughness value with and without laser i.e., melting (Kruth et al., 2010).

\subsection{The effect of microstructure and fabrication on the quality and mechanical properties.}

In terms of sample quality, the SLM process investigated in this study delivers a better surface roughness $\mathrm{Ra}$ on the surface that is parallel to the build direction. This means that the surfaces perpendicular to the laser are rougher, and this is due to the rippling effect, scan tracks and elevated solidification ridges that arise at the edge of samples. Fig 9 summarises this by showing how the surfaces perpendicular to the laser have rough surfaces. However, here, these differences in surface quality are not related directly to mechanical properties. On the other hand, these results have proven that the build direction has an influence on the microstructure of the samples produced, as shown in Figures 2 and 3, since the samples built in the zx direction have more irregular pores and more partially melted particles stacked onto 
the parallel surface. In contrast, samples manufactured in the xz direction present fewer pores and dendritic grains due to good consolidation. These microstructures gave a very clear indication of how to predict the mechanical properties of the samples. So, under these conditions, it can be concluded that the influence of the build direction on mechanical properties is greater due to the difference of the microstructure, especially in relation to the fracture toughness and the ultimate tensile strength.

The $\mathrm{xz}$ samples record the lowest value of hardness, which means the microstructure (the dendritic grains) have more ductility than the other samples in $\mathrm{zx}$ and $\mathrm{yx}$, as well as high strength, see Table 2, and this lead to a high fracture toughness value due to the higher energy absorption of the material.

In the context of the literature on this subject it can be concluded that the mechanical properties of the SLM of 316L stainless steel components are comparable to those made from conventional materials, apart from the ductility $(30 \%-51 \%)$ and the Hardness $(173 \mathrm{HV}-$ 225HV) (Azom, 2016), and similar Hardness values in SLM processed components of 316L (Cherry et al., 2015), but they are relatively lower in terms of fracture toughness (Kalu, 2013; Soboyejo, 2002). All of the results discussed in this experiment are only valid for the range of experimental processes considered in this study.

\section{Summary}

This paper has investigated the density, surface quality, microstructure and mechanical properties of the components of the SLM parts made at different building orientations. It illustrates the effects of different building orientations on the microstructures and the mechanical properties, especially the fracture toughness of the 316L stainless steel after it was fabricated by SLM. Below, we summarise the major findings:

Samples fabricated in the yx and zx orientations presented defects, such as pores and cracks, which affect the fracture toughness, strength and total elongation.

The density of the SLM parts is around $96 \%$ in comparison to the conventional product in AISI 316L stainless steel.

The tensile properties for the parts produced are good in a particularly total elongation of between $35 \%$ and $41 \%$, and the tensile and yield strengths are seen to be quite high in comparison to previous research. Special mention should also be given to the yield strength and tensile strength, which are higher than those in conventional material while maintaining the high elongation values.

In the fracture toughness test (SENB), the results of anisotropy and the values are slightly lower than those in conventional products (average values from $145.5 \mathrm{MPa} \mathrm{m}^{1 / 2}$ to $176 \mathrm{MPa}$ $\mathrm{m}^{1 / 2}$ at room temperature). 
Vickers Hardness Test results are similar to those found in conventional products made of this alloy, and the value of the hardness decreases with an increase in toughness.

The fracture surface and the microstructure show evidence of voids, cracks and pores in the samples produced in the yx and zx build orientation, and a few pores are present in samples with an $x z$ building orientation with dendrite grains.

The orientation during the build affects the mechanical properties, particularly fracture toughness. The weakest build strategy recorded was in the $\mathrm{zx}$ direction, because of pores, voids and cracks that are present at the edges of the parts.

Dendritic grains appear in the xz parts due to a high temperature gradient and fast cooling, which seem to increase the toughness and ductility while the number of pores decreases.

Most pores had aspherical shapes, and sizes of between $10 \mu \mathrm{m}$ to $150 \mu \mathrm{m}$ in the yx built parts and $10 \mu \mathrm{m}$ to $67 \mu \mathrm{m}$ in the zx built parts, which also recorded the highest porosity.

Build orientation has a slight effect on surface roughness, with the xz built samples having 3.8Ra roughness, while this is increased to $4.7 \mathrm{Ra}$ in the yx and zx built parts. Further work such as Hot Isostatic Press (HIP) treatment or re-melting could be improve the mechanical properties, surface roughness and reduce the internal stress.

With regards to the manufacture of stainless steel components for use in the aerospace industry, or indeed other industries where fracture toughness and strength are critical, it is clear that parts should be designed so they can be made in ALM with the highest in services load carried in the build direction $\mathrm{z}$ direction. Furthermore designers and manufacturers should be aware that because of the inherent limitations of ALM in surface roughness parts will require subsequent heat treatments in order to solve stress concentration problems at sharp corners and fillets. Solidification ridges near sample edges mean that post-processing may be required if such features are critical.

\section{References}

Badrossamay, M., \& Childs, T. (2006). Layer formation studies in selective laser melting of steel powders. Paper presented at the Proc. SFF Symp., Austin, Texas, USA.

Boisselier, D., \& Sankaré, S. (2012). Influence of powder characteristics in laser direct metal deposition of SS316L for metallic parts manufacturing. Physics Procedia, 39, 455463.

Chen, X., Xie, J., \& Fox, P. (2004). Direct laser remelting of iron with addition of boron. Materials Science and Technology, 20(6), 715-719.

Cherry, J., Davies, H., Mehmood, S., Lavery, N., Brown, S., \& Sienz, J. (2015). Investigation into the effect of process parameters on microstructural and physical properties of 316L stainless steel parts by selective laser melting. The International Journal of Advanced Manufacturing Technology, 76(5-8), 869-879.

Childs, T., \& Hauser, C. (2005). Raster scan selective laser melting of the surface layer of a tool steel powder bed. Proceedings of the Institution of Mechanical Engineers, Part B: Journal of Engineering Manufacture, 219(4), 379-384. 
Childs, T., Hauser, C., \& Badrossamay, M. (2005). Selective laser sintering (melting) of stainless and tool steel powders: experiments and modelling. Proceedings of the Institution of Mechanical Engineers, Part B: Journal of Engineering Manufacture, 219(4), 339-357.

Chirita, G., Stefanescu, I., Cruz, D., Soares, D., \& Silva, F. (2010). Sensitivity of different Al-Si alloys to centrifugal casting effect. Materials \& Design, 31(6), 2867-2877.

de Lima, M. S. F., \& Sankaré, S. (2014). Microstructure and mechanical behavior of laser additive manufactured AISI 316 stainless steel stringers. Materials \& Design, 55, 526532.

Ejiofor, J., \& Reddy, R. (1997). Developments in the processing and properties of particulate Al-Si composites. JOM, 49(11), 31-37.

Fischer, P., Romano, V., Weber, H. P., Karapatis, N. P., Boillat, E., \& Glardon, R. (2003). Sintering of commercially pure titanium powder with a Nd:YAG laser source. Acta Materialia, 51(6), 1651-1662. doi: http://dx.doi.org/10.1016/S1359-6454(02)00567-0

Gäumann, M., Henry, S., Cleton, F., Wagniere, J.-D., \& Kurz, W. (1999). Epitaxial laser metal forming: analysis of microstructure formation. Materials Science and Engineering: A, 271(1), 232-241.

Gu, D., \& Shen, Y. (2009). Balling phenomena in direct laser sintering of stainless steel powder: metallurgical mechanisms and control methods. Materials \& Design, 30(8), 2903-2910.

Hao, L., Dadbakhsh, S., Seaman, O., \& Felstead, M. (2009). Selective laser melting of a stainless steel and hydroxyapatite composite for load-bearing implant development. Journal of Materials Processing Technology, 209(17), 5793-5801.

John, F. (2001). Ready: LIA Handbook of Laser Materials Processing. Laser Institute of America Magnolia Publishing Inc, 181-183.

Kaiser, R., Williamson, K., O’Brien, C., Ramirez-Garcia, S., \& Browne, D. (2013). The influence of cooling conditions on grain size, secondary phase precipitates and mechanical properties of biomedical alloy specimens produced by investment casting. J Mech Behav Biomed Mater, 24, 53-63.

Kalu, I. (2013). Numerical Modeling Of Wellbore Instability (SHEAR Failure) Using Fracture Mechanics Approach.

Kruth, J.-P., Badrossamay, M., Yasa, E., Deckers, J., Thijs, L., \& Van Humbeeck, J. (2010). Part and material properties in selective laser melting of metals. Paper presented at the Proceedings of the 16th International Symposium on Electromachining.

Leskovšek, V., Ule, B., \& Liščić, B. (2002). Relations between fracture toughness, hardness and microstructure of vacuum heat-treated high-speed steel. Journal of Materials Processing Technology, 127(3), 298-308.

Mallapur, D., Rajendra Udupa, K., \& Kori, S. (2010). Influence of grain refiner and modifier on the microstructure and mechanical properties of a 356 alloy. International Journal of Engineering Science and Technology, 2(9), 4487-4493.

Maloy, S., James, M., Willcutt, G., Sommer, W., Sokolov, M., Snead, L., . . . Garner, F. (2001). The mechanical properties of 316L/304L stainless steels, Alloy 718 and Mod 9Cr-1Mo after irradiation in a spallation environment. Journal of Nuclear Materials, 296(1), 119-128.

Morgan, R., Sutcliffe, C. J., \& O'Neill, W. (2004). Density analysis of direct metal laser remelted 316L stainless steel cubic primitives. Journal of Materials Science, 39(4), 1195-1205. doi: 10.1023/B:JMSC.0000013875.62536.fa

Mumtaz, K., \& Hopkinson, N. (2010). Selective laser melting of Inconel 625 using pulse shaping. Rapid Prototyping Journal, 16(4), 248-257. 
Osakada, K., \& Shiomi, M. (2006). Flexible manufacturing of metallic products by selective laser melting of powder. International Journal of Machine Tools and Manufacture, 46(11), 1188-1193.

Osorio, W. R., Goulart, P. R., Garcia, A., Santos, G. A., \& Neto, C. M. (2006). Effect of dendritic arm spacing on mechanical properties and corrosion resistance of $\mathrm{Al} 9 \mathrm{Wt}$ Pct Si and Zn 27 Wt Pct Al alloys. Metallurgical and Materials Transactions A, 37(8), 2525-2538.

Rombouts, M. (2006). Selective Laser Sintering/Melting of Iron-Based Powders (Selectief laser sinteren/smelten van ijzergebaseerde poeders).

Rombouts, M., Froyen, L., Bourell, D., \& Kruth, J. (2005). Roughness after laser melting of iron based powders. Paper presented at the Proc. 2nd Int. Conf. on Advanced Research in Virtual and Rapid Prototyping VRAP, Leiria, Portugal.

Schoinochoritis, B., Chantzis, D., \& Salonitis, K. (2015). Simulation of metallic powder bed additive manufacturing processes with the finite element method: A critical review. Proceedings of the Institution of Mechanical Engineers, Part B: Journal of Engineering Manufacture, 0954405414567522.

Soboyejo, W. (2002). Mechanical properties of engineered materials (Vol. 152): CrC Press.

Strano, G., Hao, L., Everson, R. M., \& Evans, K. E. (2013). Surface roughness analysis, modelling and prediction in selective laser melting. Journal of Materials Processing Technology, 213(4), 589-597.

Takalo, T., Suutala, N., \& Moisio, T. (1979). Austenitic solidification mode in austenitic stainless steel welds. Metallurgical Transactions A, 10(8), 1173-1181.

Tolochko, N. K., Mozzharov, S. E., Yadroitsev, I. A., Laoui, T., Froyen, L., Titov, V. I., \& Ignatiev, M. B. (2004). Balling processes during selective laser treatment of powders. Rapid Prototyping Journal, 10(2), 78-87. doi: doi:10.1108/13552540410526953

Yan, C., Hao, L., Hussein, A., \& Raymont, D. (2012). Evaluations of cellular lattice structures manufactured using selective laser melting. International Journal of Machine Tools and Manufacture, 62, 32-38.

Yang, Y., Lu, J.-b., Luo, Z.-Y., \& Wang, D. (2012). Accuracy and density optimization in directly fabricating customized orthodontic production by selective laser melting. Rapid Prototyping Journal, 18(6), 482-489.

Yasa, E., \& Kruth, J.-P. (2011). Microstructural investigation of Selective Laser Melting 316L stainless steel parts exposed to laser re-melting. Procedia Engineering, 19, 389395.

Zhang, L. C., Klemm, D., Eckert, J., Hao, Y. L., \& Sercombe, T. B. (2011). Manufacture by selective laser melting and mechanical behavior of a biomedical $\mathrm{Ti}-24 \mathrm{Nb}-4 \mathrm{Zr}-8 \mathrm{Sn}$ alloy. Scripta materialia, 65(1), 21-24. doi: http://dx.doi.org/10.1016/j.scriptamat.2011.03.024 http://www.azom.com/properties.aspx?ArticleID=863 - 18:30 - 26/05/2015 